\title{
Commentary
}

\section{Risk of COVID-19 infection in workplace settings and the use of personal protective equipment}

\author{
Leila Omidi ${ }^{\mathrm{a}}$, Gholamreza Moradi ${ }^{\mathrm{b}, *}$ and Nasim Mostofi Sarkari ${ }^{\mathrm{b}}$ \\ ${ }^{a}$ Department of Occupational Health Engineering, School of Public Health, Tehran University \\ of Medical Sciences, Tehran, Iran \\ ${ }^{\mathrm{b}}$ Department of Occupational Health Engineering, School of Health, Tabriz University \\ of Medical Sciences, Tabriz, Iran
}

Received 3 May 2020

Accepted 9 May 2020

Many workers in different occupational settings are occupationally exposed to health and safety hazards $[1,2]$. Biological contaminants in workplaces can cause adverse health effects in exposed workers [3,4]. Coronavirus disease 2019 (COVID-19) (an infectious disease) has spread very quickly and the World Health Organization (WHO) declared the COVID19 outbreak a global pandemic on 11 March 2020. The outbreak of COVID-19 is considered as a global public health concern $[5,6]$.

The activities of some industries such as petrochemical plants, power plants, water treatment plants, food manufacturing plants, sanitary ware manufacturing plants, etc., cannot be stopped even during an outbreak of diseases and workers should be present in their workplaces and have to work to provide products/services. Also, the presence of healthcare staff, such as workers providing frontline care for COVID-19 in the hospitals, is essential. In such situations, it seems necessary to protect workers in workplace settings against coronavirus-induced diseases.

*Address for correspondence: Gh Moradi, Department of Occupational Health Engineering, School of Health, Tabriz University of Medical Sciences, Tabriz, Iran. E-mail: moradig@ tbzmed.ac.ir.
The main routes of transmission of COVID-19 appear to occur through close contact between people and droplets [7]. When a person is in close contact with an infected person in families, communities, and other public places, she/he may be at increased risk for exposure to the virus $[8,9]$. In workplaces, one of the main ways COVID-19 spreads is through touching of contaminated surfaces by workers. To prevent the spread of COVID-19 in workplaces, surfaces (e.g. desks and tables) and objects (e.g. telephones, keyboards) touched by workers should be wiped with disinfectant regularly. Sanitizing hand rub dispensers should be put in prominent places and face masks (ordinary medical masks) or paper tissues should be provided for those who develop a runny nose or cough at work [10]. In workplace settings, the use of appropriate personal protective equipment (PPE) for protecting workers against COVID-19 infection must also be taken into consideration by employers.

One of the most important and effective pieces of PPE are respiratory protection devices such as face masks. Face masks such as surgical or medical procedure masks are disposable devices and can create a physical barrier between potential contaminants in the environment and human nose and mouth [11]. According to WHO, based on the risk of exposure and the transmission dynamics of the virus, the 
appropriate PPE should be selected. In workplaces and for protecting workers in industrial settings, wearing a medical mask is necessary for persons with respiratory symptoms or those caring for COVID19 patients in their home [12]. For healthcare staff, caring for multiple patients, the N95, filtering facepiece (FFP) 2, or FFP3 respirator with a tight facial fit can provide efficient filtration and protect healthcare workers against potentially hazardous particles $[12,13]$. The use of a fit-tested N95 respirator has been shown to be more effective in clinical respiratory infection and influenza illness for healthcare workers than medical masks [14]. For the COVID19 pandemic, the effective respirator must fit tightly to the wearer's face and supportive protection using masks or N95 respirators can protect the wearers from microorganism transmission. The better outcome of N95 respirators compared with medical masks against COVID-19 infection transmission has not been fully examined [15]. Also, the half-face medical protection mask (N99) had more than 99\% filtration efficiency for the viral aerosol and can protect the wearers from viral aerosol disease transmission [16].

Healthcare workers should also use appropriate PPE such as gowns, gloves, and eye protection (goggles or face shields) [10].

In conclusion, in this critical situation, proper hygiene practices and workplace controls such as using appropriate PPE in workplaces must be considered to protect workers' health from the risks of COVID-19 infection [17].

\section{Conflict of interest}

The authors state no conflict of interest.

\section{References}

[1] Jafari MJ, Khajevandi AA, Najarkola SAM, Yekaninejad MS, Pourhoseingholi MA, Omidi L, et al. Association of sick building syndrome with indoor air parameters. Tanaffos. 2015;14(1):55.

[2] Zarei F, Rezazadeh Azari M, Salehpour S, Khodakarim S, Omidi L, Tavakol E. Respiratory effects of simultaneous exposure to respirable crystalline silica dust, formaldehyde, and triethylamine of a group of foundry workers. Journal of Research in Health Sciences. 2017;17(1):e00371.
[3] Jafari MJ, Hajgholami MR, Omidi L, Jafari M, Tabarsi P, Salehpour S, et al. Effect of Ventilation on Occupational Exposure to Airborne Biological Contaminants in an Isolation Room. Tanaffos. 2015;14(2):141.

[4] Jafari MJ, Hajgholami MR, Jafari M, Amiri Z, Omidi L, Salehpour S, et al. Assessment of the effectiveness of ventilation types for reducing the occupational exposure to bioaerosols in health care staffs. Journal of Occupational Hygiene Engineering. 2015;1(4):1-10.

[5] Cucinotta D, Vanelli M. WHO Declares COVID19 a Pandemic. Acta bio-medica: Atenei Parmensis. 2020;91(1):157.

[6] WHO. WHO Director-General's opening remarks at the media briefing on COVID-19 - 11 March. 2020; Available from: https://www.who.int/dg/speeches/detail/who-directo r-general-s-opening-remarks-at-the-media-briefing-on-covi d-19-11-march-2020.

[7] WHO. Rational use of personal protective equipment for coronavirus disease 2019 (COVID-19). World Health Organization; 2020, February 27; Available from: https://apps. who.int/iris/bitstream/handle/10665/331215/WHO-2019nCov-IPCPPE_use-2020.1-eng.pdf.

[8] Wang J, Du G. COVID-19 may transmit through aerosol. Irish Journal of Medical Science (1971-). 2020:1-2.

[9] Qiao J. What are the risks of COVID-19 infection in pregnant women? The Lancet. 2020;395(10226):760-2.

[10] WHO. Getting your workplace ready for COVID-19: How COVID-19 spreads, 19 March 2020. World Health Organization, 2020.

[11] FDA. N95 Respirators and Surgical Masks (Face Masks). Food and Drug Administration (FDA); 2018; Available from: https://www.fda.gov/medical-devices/personal-prote ctive-equipment-infection-control/n95-respirators-and-surg ical-masks-face-masks

[12] WHO. Rational use of personal protective equipment (PPE) for coronavirus disease (COVID-19): interim guidance. World Health Organization, 2020, 19 March

[13] Repici A, Maselli R, Colombo M, Gabbiadini R, Spadaccini M, Anderloni A, et al. Coronavirus (COVID-19) outbreak: what the department of endoscopy should know. Gastrointestinal Endoscopy. 2020.

[14] MacIntyre CR, Chughtai AA, Rahman B, Peng Y, Zhang $\mathrm{Y}$, Seale $\mathrm{H}$, et al. The efficacy of medical masks and respirators against respiratory infection in healthcare workers. Influenza and other Respiratory Viruses. 2017;11(6):511-7.

[15] Wang Q, Yu C. Letter to editor: Role of masks/respirator protection against 2019-novel coronavirus (COVID-19). Infection Control \& Hospital Epidemiology. 2020:1-7.

[16] Wen Z, Lu J, Li J, Li N, Zhao J, Wang J, et al. Determining the filtration efficiency of half-face medical protection mask (N99) against viral aerosol. Aerobiologia. 2010;26(3):24551.

[17] OSHA. Guidance on Preparing Workplaces for COVID19.: Occupational and Safety Health Administration; 2020; Available from: https://www.osha.gov/Publications/ OSHA3990.pdf 